\title{
Virtual Instruction: Issues and Insights from an International Perspective
}

Carine Feyten and Joyce Nutta. Colorado: Libraries Unlimited, 1999, 262 pp. ISBN 1-56308-714-6

This is a timely book that explores virtual instruction from a global perspective. It begins by defining virtual instruction as computer-mediated instruction that involves active learning-type interactions, instruction taking place from a distance and synchronous or asynchronous communication - that is, the instructor may or may not be present at the time the students are engaged in learning. The authors give as examples of virtual instruction: e-mail, Web-based instruction, Internet relay chat, CUseeMe and two-way video conferencing. The book clarifies the point that virtual instruction is not synonymous with the more traditional distance learning-type courses which may include correspondence courses, one-way satellite television, videotaped instruction or televised courses, since none of these forms has one of the key elements that must be associated with virtual instruction: it should be interactive.

One of the book's major strengths is that it does not presume an understanding of, or experience with, virtual instruction. It is not written in 'techese' and therefore will appeal to readers with little background in technological matters. At the same time, it is written with enough depth to also be of interest to those with significant levels of technical expertise. Furthermore, because it reflects the state of virtual instruction around the world, the book has universal appeal and readers from any country will find it informative.

The book is very well structured. It begins with definitions of virtual instruction and moves on to an examination of what is involved in the establishment of a virtual instruction program in an educational institution. Of particular interest to those faced with the challenge of setting up such a program for their organization, will be the chapter on the cost-effectiveness of this approach to teaching and learning. Many cost-related issues which may not readily come to mind are thoroughly explored. The author of this chapter argues that not all costs can be weighted equally and that some costs are well worth bearing because of the payback the students, teachers and the educational institution will receive, while other costs are clearly not.

The book goes on to consider the strengths and weaknesses associated with virtual instruction, the changing roles of teachers and students and the impact it has had and, will likely continue to have, on teaching, learning and educational institutions. It is particularly interesting, and perhaps a little disconcerting to read about the physical and attitudinal changes that will have to take place in educational institutions before virtual instruction programs can be implemented.

What makes this book stand out from other examinations of this phenomenon, is the fact that each chapter is written by a different contributor who has expertise in the field of virtual instruction in his or her home country. We are able to see how different countries are approaching the development and maintenance of 
virtual instruction programs. It is of great interest to note how issues related to virtual instruction seem to transcend borders and cultural realities. Whether the program in question is in North America, Europe, Asia or elsewhere, similar issues seem to come to the forefront when virtual instruction is explored.

Virtual instruction is a relatively new approach to teaching and learning. Although some research has been carried out in this area, there is definitely a dearth of published information on the topic. Thanks to the wide range of issues explored in this book, many avenues for future research present themselves for inquisitive and enterprising researchers.

Finally, the book represents a very comprehensive and up-to-date look at the state of virtual instruction around the world. It is highly recommended to instructors of any nationality interested in exploring the possibility of offering courses through virtual instruction, as well as to educational administrators who have the responsibility of setting up virtual instruction programs in their institutions. It is very readable, engagingly informative and thus, well worth adding to any professional library.

Janet Flewelling University of Windsor 